\title{
The Biosynthetic Basis of Adult Lactase Deficiency
}

\author{
John Witte, Mark Lloyd, Vilja Lorenzsonn, Helen Korsmo, and Ward Olsen \\ Gastroenterology Research Laboratory, William S. Middleton Memorial Veterans Hospital, \\ and Department of Medicine, University of Wisconsin, Madison, Wisconsin 53705
}

\begin{abstract}
The intestinal brush-border enzyme lactase splits lactose into its component monosaccharides, glucose and galactose. Relative deficiency of the enzyme during adulthood is a common condition worldwide and is frequently associated with symptoms of lactose intolerance. We studied the synthesis and processing of lactase in normal and adult hypolactasic subjects using human intestinal explants in organ culture. Metabolic labeling experiments in our control subjects with [ ${ }^{35}$ S]methionine followed by immunoprecipitation, sodium dodecyl sulfate-polyacrylamide-gel electrophoresis, and fluorography demonstrated that newly synthesized lactase is initially recognized as a precursor molecule with a relative molecular weight $\left(M_{r}\right)$ of 205,000. Over the course of several hours most of the labeled lactase was converted to a mature form of $150,000 M_{\mathrm{r}}$. Transiently appearing forms of 215,000 and $190,000 M_{\mathrm{r}}$ were identified and were felt to represent intermediary species generated during intracellular processing.

We identified two distinct alterations in lactase biosynthesis accounting for adult hypolactasia. Studies in three deficient subjects demonstrated markedly reduced synthesis of the precursor protein though posttranslational processing appeared identical to normal. Multiple studies in a fourth deficient subject demonstrated synthesis of ample amounts of precursor lactase but reduced conversion to the mature active form of the enzyme. (J. Clin. Invest. 1990. 86:1338-1342.) Key words: lactase $\bullet$ lactase deficiency $\bullet$ adult hypolactasia
\end{abstract}

\section{Introduction}

Lactase is an integral protein of the small intestinal brush border membrane which hydrolyzes dietary lactose, the sugar of milk, to its component monosaccharides, glucose and galactose. In most mammals, lactase levels are appropriately high during the postnatal stage of development when milk is the sole or major dietary constituent. However, during wean-

Presented in part as an abstract (1989. Gastroenterology. 96:A549) and at the annual meeting of the American Gastroenterological Association, Washington, DC, 1989.

Address correspondence to Mark Lloyd, M.D., Gastroenterology Research Laboratory, Middleton Veterans Administration Hospital, 2500 Overlook Terrace, Madison, WI 53705.

Received for publication 20 December 1989 and in revised form 4 May 1990.

J. Clin. Invest.

(C) The American Society for Clinical Investigation, Inc. $0021-9738 / 90 / 10 / 1338 / 05 \$ 2.00$

Volume 86, October 1990, 1338-1342 ing, enzyme activity substantially declines to levels 5-10\% of those present at birth. In most humans, programmed loss of enzyme activity occurs during childhood, but persistence of lactase throughout life is not uncommon and is the norm in certain racial groups $(1,2)$. Whereas recent studies of the molecular biology of human lactase have provided important information concerning the evolution and structure of the protein $(3,4)$, the regulatory mechanisms controlling enzyme expression remain to be determined. To begin to understand the molecular events responsible for the developmental decline in lactase, we studied the biosynthesis of the protein in intestinal explants from subjects with adult hypolactasia and adults with high enzyme levels. We identified two distinct alterations responsible for hypolactasia. Studies in three subjects demonstrated reduced synthesis of a lactase precursor and in a fourth an alteration in posttranslational processing.

\section{Methods}

Subjects. Multiple duodenal biopsies (average weight, $12 \mathrm{mg} /$ biopsy) were obtained with a 9 French biopsy forceps during diagnostic upper gastrointestinal endoscopy. Biopsy specimens were immediately immersed in ice-cold oxygenated Krebs-Ringer bicarbonate buffer and were transfered to organ culture medium within $15 \mathrm{~min}$. One biopsy was processed for histologic examination and a second homogenized and assayed for lactase and sucrase specific activities (5). Neither control subjects nor hypolactasic subjects had clinical, endoscopic, or histologic evidence of mucosal disease. Three control subjects had levels of lactase specific activity (24-30 U/g protein) within the normal range reported by Welsh et al. (1). Four subjects had low lactase levels (4-12 $\mathrm{U} / \mathrm{g}$ ) but normal sucrase activity, consistent with adult hypolactasia. None had a history suggestive of congenital lactase deficiency. Hypolactasic subjects 1 and 2 were of Mediterranean descent. Subjects 3 and 4 were of Scandinavian and Native American heritage, respectively.

Organ-culture experiments. Pulse-chase experiments were performed as previously reported by us $(6,7)$. Some experiments were performed with continuous labeling for variable periods up to $20 \mathrm{~h}$. Labeled explants were frozen intact at $-70^{\circ} \mathrm{C}$ and subsequently processed within $3 \mathrm{~d}$.

Immunoprecipitation. The labeled mucosal explants were thawed and homogenized in $1.0 \mathrm{ml}$ of phosphate-buffered saline containing $1 \%$ Triton X-100, pH 7.5, using 20 strokes of the Potter-Elvehjem tissue homogenizer (Thomas Scientific, Swedesboro, NJ). Total protein in the tissue homogenates was determined by protein assay (BioRad Laboratories, Richmond, CA). Radioactivity incorporated into total protein was determined as follows: an aliquot of the homogenate was precipitated with $20 \%$ trichloroacetic acid (TCA), washed twice with $5 \%$ TCA, then dissolved in $0.3 \mathrm{~N} \mathrm{NaOH}$. The dissolved protein was subsequently added to Opti-fluor scintillation mixture (Packard Instrument Co., Inc., Downers Grove, IL) and total radioactivity determined in a Beta trac 6895 liquid scintillation spectrometer (Tracor Analytic, Elk Grove Village, IL). The remaining homogenate was incubated at $4^{\circ} \mathrm{C}$ for $2 \mathrm{~h}$, then centrifuged at $27,000 \mathrm{~g}$ for $1 \mathrm{~h}$. The supernatant was precleared twice by incubating with $75 \mu 1$ Pansorbin 
(Calbiochem-Behring Corp., La Jolla, CA) at $4^{\circ}$ for $30 \mathrm{~min}$ and centrifuging for $5 \mathrm{~min}$ in a Microfuge 12 (Beckman Instruments, Inc., Fullerton, CA). Lactase and sucrase-isomaltase were immunoprecipitated from separate aliquots of the cleared supernatant by incubating overnight at $4^{\circ} \mathrm{C}$ with an excess of monoclonal antibodies directed against human lactase $(\mathrm{H} 31 \mathrm{C} 4 \mathrm{C} 3)$ or human sucrase-isomaltase (H40D4C5). In all comparative studies experimental conditions were identical between subjects, and lactase and sucrase-isomaltase were immunoprecipitated from tissue homogenates adjusted to contain equal amounts of radiolabeled total protein. Collection of the precipitate was enhanced by exposure to Pansorbin at $4^{\circ} \mathrm{C}$ for $30 \mathrm{~min}$ immediately before centrifugation. The immunoprecipitates were recovered by centrifugation and washed four times with $0.15 \mathrm{M} \mathrm{NaCl}$ containing $0.02 \%$ sodium dodecyl sulfate (SDS), $0.1 \%$ Triton X-100, and $50 \mathrm{mM}$ Tris- $\mathrm{HCl}, \mathrm{pH} 7.4$ then three times with the same buffer without detergents. In all experiments, homogenization and immunoisolation were performed in the presence of the following protease inhibitors: aprotinin $(1 \mu \mathrm{g} / \mathrm{ml}$ final concentration), phenylmethyl sulfonyl fluoride ( 1 $\mathrm{mM})$, leupeptin $(10 \mu \mathrm{g} / \mathrm{ml})$, and EDTA $(100 \mu \mathrm{M})$. The adequacy of the immunoisolation procedure was assured by determination of lactase activities in the tissue homogenates before and after immunoprecipitation.

SDS polyacrylamide gel electrophoresis. The immunoprecipitates were solubilized with $60 \mu \mathrm{l}$ of electrophoresis buffer containing $2 \%$ SDS and 5\% 2-mercaptoethanol (Bio-Rad Laboratories) heated to $100^{\circ} \mathrm{C}$ in a boiling water bath for $5 \mathrm{~min}$, then applied to $5 \%$ polyacrylamide gels for electrophoresis using the buffer system of Laemmli (8). Gels were developed with silver stain using the technique of Heukeshoven (9) then treated with EN ${ }^{3}$ HANCE (New England Nuclear, Boston, MA), dried on filter paper, and exposed to X-OMAT AR film (Eastman Kodak Co., Rochester, NY) for $3-28 \mathrm{~d}$ at $-70^{\circ} \mathrm{C}$ to yield the completed fluorograms. Quantification of radioactivity on the fluorograms was carried out by densitometric scanning of radiolabeled bands using the GS 300 Scanning Densitometer (Hoefer Scientific Instruments, San Francisco, CA).

Glycosidase experiments. Enzymatic probes that cleave oligosaccharide side chains from glycoproteins were used to investigate the glycosylation of newly synthesized lactase. Experiments using endo- $\beta$ $N$-acetylglucosaminidase (endo $\mathrm{H}$ ) (Miles Laboratories Inc., Naperville, IL) and peptide: $N^{4}-(N$-acetyl- $\beta$-glucosaminyl) asparagine amidase (PNGase F) (Genzyme Corp., Boston, MA) were conducted according to the methods previously described (7).

Preparation of antibodies. Monoclonal antibodies were prepared at the Hybridoma Facility of the University of Wisconsin using the Facility's modification (1985) of the method of Galfre and Milstein (10) as previously described by us (7). Ascities prepared from positive valid clones were purified on MAPS II columns (Bio-Rad Laboratories). 30 $\mu \mathrm{g}$ of protein A-Sepharose bound monoclonal IgG (H31C4C3) removed $99 \%$ of lactase activity from a Triton X-100 solubilized microvillar membrane preparation with no detectable binding of sucrase, isomaltase, trehalase, aminooligopeptidase, or alkaline phosphatase activity. The monoclonal antibody (H40D4C5) binds specifically to human sucrase-isomaltase under these conditions and has been used by us in previous immunoisolation studies (7).

\section{Results}

Normal subjects. Fluorograms from pulse-chase studies in normal subjects showed a single $205-\mathrm{kD}$ precursor lactase band within 30 min of chase (not shown). While densitometry demonstrated that this molecular form represented $70 \%$ of labeled lactase at $60 \mathrm{~min}$, an additional $190-\mathrm{kD}$ band was also identified at that time (Fig. 1). At later time points the smaller molecular form was detected as a more diffuse band on fluorography, and densitometric scanning confirmed that this was the predominant species from 3 to $8 \mathrm{~h}$ of chase. The relative

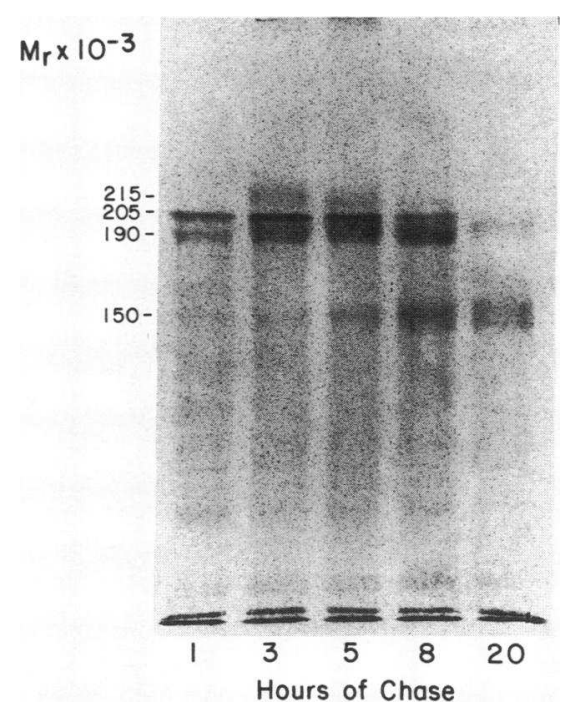

Figure 1. Fluorogram generated by a pulse-chase study in a control subject. Immunoprecipitated lactase was initially recognized as a 205-kD protein that was gradually converted to the mature $150-\mathrm{kD}$ molecule over $20 \mathrm{~h}$. Intermediate forms of 215 and $190 \mathrm{kD}$ were identified.

distribution of the different molecular forms of lactase are displayed as a function of time in Fig. 2. This shows that the amount of newly synthesized lactase represented by the 205$\mathrm{kD}$ band progressively diminished over the chase period, accounting for only $12 \%$ of the labeled protein by $8 \mathrm{~h}$. A highermolecular-weight form of $215 \mathrm{kD}$ was detected at 3 and $5 \mathrm{~h}$ of chase. This band appeared transiently and was only faintly detectable in some patients. At the same time the higher-molecular-weight lactase appeared, another form of the protein was detected at $150 \mathrm{kD}$, the size of mature brush border membrane lactase. The $150-\mathrm{kD}$ form progressively accumulated at all later time points and was the predominant band after $20 \mathrm{~h}$ of chase, representing $75 \%$ of the labeled protein. Continuous

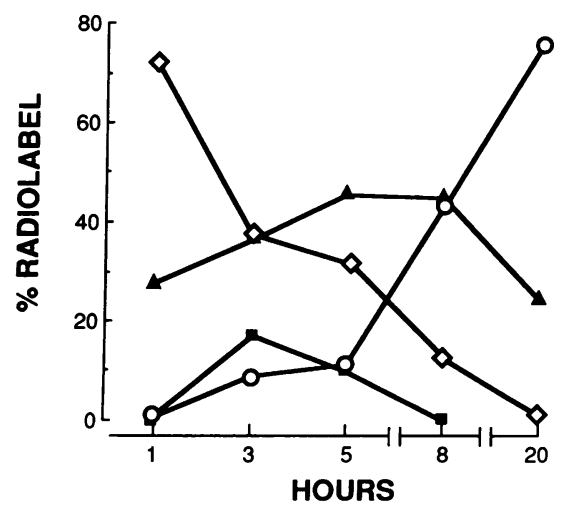

Figure 2. Relative distribution of the molecular forms of labeled lactase as a function of time. Densitometric scanning of the fluorogram shown in Fig. 1 demonstrates that the 205-kD form $(\diamond)$ gradually disappeared as the $150-\mathrm{kD}$ species (0) accumulated. The $190-\mathrm{kD}$ form of lactase ( $\Delta$ ) represents a predominate intermediate that appeared to accumulate and then dissipate during processing. The $215-\mathrm{kD}$ protein ( $\square$ ) was rapidly converted to other molecular forms and was only transiently demonstrated. 


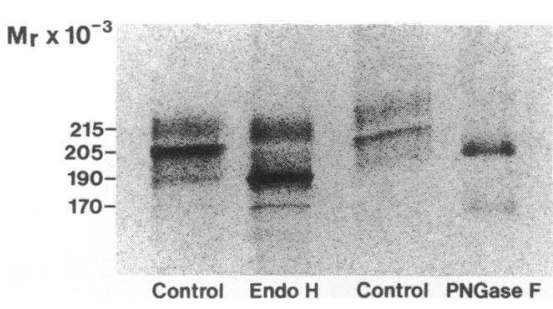

Figure 3. Fluorogram of high-molecular-weight forms of lactase after glycosidic digestion. The band at $205 \mathrm{kD}$ generates a $190-\mathrm{kD}$ form after incubation with endo $\mathrm{H}$ while the $215-\mathrm{kD}$ species shows no change in migration, findings characteristic of high-mannose and complex forms of glycoproteins, respectively. The band spanning 190 to $205 \mathrm{kD}$ is composed of a mixture of both high-mannose and complex forms. Digestion with PNGase F generates two bands derived from the newly synthesized precursor and the proteolytic intermediate.

labeling studies showed similar results with conversion of high-molecular-weight precursors to mature lactase over time.

To assess the state of glycosylation of the molecular forms, susceptibility both to endo $\mathrm{H}$, which cleaves immature, highmannose $N$-linked carbohydrate chains from glycoproteins, and to PNGase F, which removes both high-mannose and complex $N$-linked carbohydrates, was determined. As shown in Fig. 3, lactase represented by the sharp band at 205 $\mathrm{kD}$ was converted to a $190-\mathrm{kD}$ band when digested with endo $\mathrm{H}$ while the $215-\mathrm{kD}$ species was not affected. This suggests that the 205-kD molecule is the high-mannose form of the enzyme while the larger molecular form arises from trimming highmannose cores and the addition of terminal sugars in the Golgi complex. The diffuse band spanning the region between 190 and $205 \mathrm{kD}$ showed sensitivity to endo $\mathrm{H}$ only along its lower border generating a discrete band at $\sim 170 \mathrm{kD}$. Most of the lactase represented in the diffuse band showed no change in migration, again implying complex glycosylation of the molecule. Glycosidic digestion of the high-molecular-weight forms of lactase using PNGase F resulted in the generation of two distinct bands confirming that the complex series of bands detected on the fluorograms are derived from the glycosylation of two proteins of different sizes: the nascent precursor and a presumed proteolytic product.

Lactase-deficient subjects. To determine if an alteration in the normal pattern of synthesis and molecular processing could account for the lack of enzyme expression in lactase-deficient subjects, we compared fluorograms generated in studies of deficient subjects with normal controls. Fluorograms from continuous labeling experiments in three lactase deficient individuals (subjects $1-3$ ) showed a normal pattern of synthesis and posttranslational processing as illustrated by the representative fluorogram in Fig. $4 \mathrm{~B}$. The relative amount of radioactivity incorporated into mature lactase after $20 \mathrm{~h}$ of labeling ranged between 35 and $55 \%$ of the total label in these deficient subjects and between 30 and $70 \%$ of total label in studies of controls. However, at all time points the total amount of radiolabel incorporated into lactase, represented by the density of fluorographic bands, was significantly less in the deficient subjects. Furthermore, there was a linear relationship between mucosal enzyme activity and the total amount of radiolabel as assessed by band densitometry for these deficient subjects and their normal control (Fig. 5). An additional band in the range of $120-130 \mathrm{kD}$ was identified at later time points in the deficient subjects, accounting for $8-28 \%$ of the radiolabeled lactase pool (Fig. 4). This band was either absent or only faintly detectable on fluorograms for normal subjects.

Tissue from a fourth lactase-deficient subject showed a qualitatively different pattern of synthesis. Although lactasespecific activity in this subject was the lowest studied, fluorograms from a continuous labeling study demonstrated substantial incorporation of radiolabel into the $205-\mathrm{kD}$ precursor molecule in amounts slightly greater than the control subject. After $20 \mathrm{~h}$, however, there was a fourfold reduction in the relative density of the $150-\mathrm{kD}$ band compared with the control, with accumulation of high-molecular-weight precursor lactase (Fig. 4). A pulse-chase study in this deficient subject showed similar results with abundant synthesis of the 205-kD high-mannose precursor (Fig. 6). This remained the predominant form through $8 \mathrm{~h}$ of chase, accounting for $65 \%$ of the labeled protein with the remainder of the equally distributed between the $190-\mathrm{kD}$ intermediate and the $150-\mathrm{kD}$ mature lactase. After $18 \mathrm{~h}$ of chase, $75 \%$ of the newly synthesized lactase had been converted to the high-molecular-weight intermediate, and only $20 \%$ of the label was detected within the mature molecule. This is in stark contrast to normal synthesis where the majority of the radiolabeled lactase pool had been converted to the $150-\mathrm{kD}$ molecule by this time.

To further characterize the biosynthetic defects in these subjects we determined the relative amounts of precursor and mature lactase in the stable in vivo lactase pool by examining silver-stained gels. In this study equal amounts of immunoprecipitated lactase enzymatic activity from tissue in subject 4 and from a deficient subject with nearly identical lactase activity (subject 3) were applied to gels and electrophoresed. Silver stained gels revealed similar amounts of the $150-\mathrm{kD}$ mature protein but substantially more precursor enzyme in subject 4 (data not shown).

Comparative pulse-chase studies in subjects 3 and 4 again demonstrated substantially greater incorporation of radiolabel

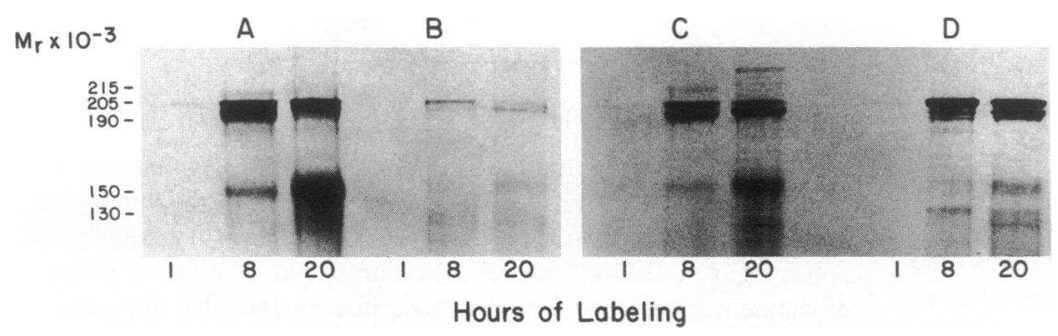

Figure 4. Fluorograms of immunoprecipitated lactase from continuous labeling studies of lactase deficient patients $(B$ and $D)$ and their respective controls $(A$ and $C$ ). Immunoprecipitation from deficient and control tissue was normalized by adjusting the mucosal homogenates to contain equal amounts of radiolabeled total protein. $B$ (subject 3 ) shows significantly less accumulation of radiolabeled lactase over time than in the control displayed in $A$. This pattern was seen in two other lactase-deficient subjects. $D$ (subject 4) demonstrates accumulation of radiolabel in precursor lactase in amounts greater than the control depicted in $C$. There was a fourfold decrease in the relative amount of precursor converted to mature lactase. 


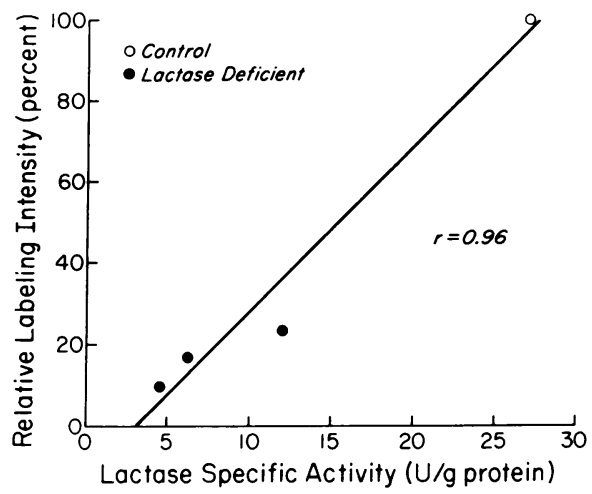

Figure 5. Relative amounts of radiolabel incorporation into lactase in deficient subjects 1-3 and their control as a function of mucosal lactase-specific activity. Incorporation was quantitated by densitometric scanning of fluorographic bands generated during $8 \mathrm{~h}$ continuous labeling studies. The linear relationship between uptake and specific activity suggests that decreased synthesis of lactase accounts for reduced levels of enzyme in phenotype $I$.

into precursor lactase in subject 4 at all time points (Fig. 7). Pulse-chase studies of sucrase-isomaltase in both subjects showed the synthesis of a 205-kD molecule which was converted to a larger molecule of $225 \mathrm{kD}$ in a fashion identical to normal (6). Therefore, the processing defect demonstrated in subject 4 appears limited to lactase.

\section{Discussion}

Studies in human and nonhuman species indicate that lactase is synthesized as a high-molecular-weight precursor molecule which undergoes cotranslational glycosylation to a high-mannose glycoprotein (11-13). The precursor is subsequently cleaved to form the mature brush border lactase. In the present study, we report the detection of a $190-\mathrm{kD}$ form of the protein that accumulates for several hours before the detection of significant amounts of mature lactase. This process is coincident with a sequential diminution in the amount of lactase present

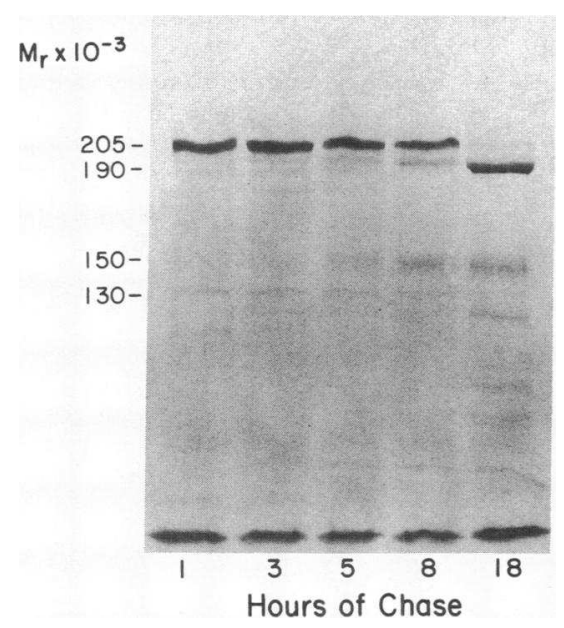

Figure 6. Fluorogram generated by a pulse-chase study in subject 4 . Lactase appeared promptly as the $205-\mathrm{kD}$ precursor, but there was little conversion of the protein to the mature $150-\mathrm{kD}$ form of the enzyme. Lactase accumulated as the $190-\mathrm{kD}$ intermediate form at $18 \mathrm{~h}$.

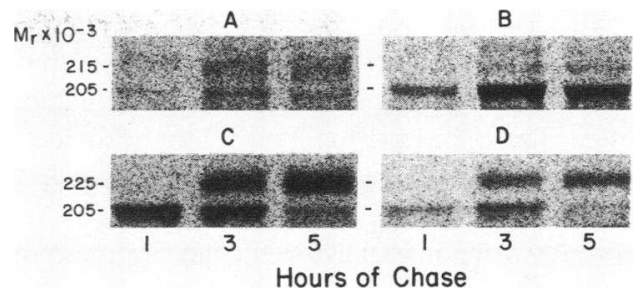

Figure 7. Fluorograms of precursor lactase (top panels) and precursor sucrase-isomaltase (bottom panels) from pulse-chase studies in deficient subjects $3(A$ and $C$ ) and $4(B$ and $D$ ). Greater lactase precursor accumulation is demonstrated at all time points in patient 4 despite similar mucosal lactase activities. Both subjects show normal processing of sucrase-isomaltase.

as the high-mannose precursor and is likely analogous to the posttranslational processing of lactase in rat where a two-step proteolytic conversion to the mature brush border form of the enzyme has been reported (13). Evidence for such a mechanism occurring in human intestine is supported by the previously reported observation of similar multiple forms of high-molecular-weight lactase in immunoprecipitates from human jejunal mucosa (14). Despite the use of protease inhibitors during sample preparation, the possibility that the $190-\mathrm{kD}$ band could result from an artefact deserves consideration. We feel that the accumulation and redistribution of this species as a function of time in multiple pulse chase studies, however, clearly supports the role of this molecular form as a true intermediary in the biosynthetic processing of human lactase.

It is not clear that the initial proteolytic cleavage occurs at a single point during posttranslational processing. While the discrete band of $190 \mathrm{kD}$ that is identified after $60 \mathrm{~min}$ of chase is likely a high-mannose form of lactase (Fig. 1), our experiments with glycosidic digestion suggest that most of the diffuse band that appears at later time points represents the complex form of the proteolytic intermediate. Certainly some of the precursor lactase undergoes complex glycosylation before the initial cleavage as evidenced by the identification of the 215 $\mathrm{kD}$ species that is endo $\mathrm{H}$ resistant. The evanescent appearance of this form of lactase in the course of these studies suggests that this species is rapidly converted to other molecular forms of the protein and therefore represents only a small fraction of the stable lactase pool.

Our studies have demonstrated that at least two different biosynthetic mechanisms are responsible for the regulation of lactase expression in humans with adult hypolactasia. Lactase deficiency in the first three subjects (phenotype I) was characterized by reduced incorporation of label into the high-molecular-weight precursor of the enzyme. However, this newly synthesized molecule subsequently underwent normal posttranslational processing and conversion to the mature enzyme. In addition we found a high correlation between radiolabeling of lactase and lactase-specific activity in these subjects and in a control, suggesting that lactase levels are generally regulated by synthetic rates of the enzyme. It is conceivable that premature degradation of newly synthesized protein rather than diminished synthesis accounted for our observations. We did identify additional bands $(130 \mathrm{kD})$ of a molecular size smaller than mature lactase in deficient subjects at later time points. Although these findings suggest that some degree of proteolytic degradation was occurring, the proteolytic fragments represented only a small portion of the total radiolabeled lactase 
pool (8-28\% in continuous labeling experiments), and pulsechase studies demonstrated reduced radiolabel incorporation into precursor lactase with no proteolytic fragments detectable at early time points. Thus, the primary biosynthetic defect responsible for low lactase levels in phenotype I subjects appears to be diminished enzyme synthesis. This conclusion is consistent with the studies of Jonas et al. on the developmental loss of lactase in rats (15).

In contrast to the defect in phenotype I, lactase biosynthesis in the fourth deficient subject (phenotype II) was characterized by normal synthesis of high-molecular-weight precursor but defective posttranslational processing of the molecule. In this case, biosynthetic studies repeatedly showed reduced conversion of precursor lactase to the mature enzyme. Comparative studies of lactase from unlabeled tissue in this subject and a subject with phenotype I deficiency (subject 3 ) were also consistent with defective cleavage of the precursor enzyme in phenotype II. Silver-stained gels showed similar amounts of mature lactase in the immune precipitates when identical amounts of enzymatic activity were precipitated but considerable amounts of precursor protein in phenotype II. These findings also imply that the mature form of lactase, but not precursor lactase, is enzymatically active. Thus, phenotype II lactase deficiency is characterized by an alteration in the conversion of inactive precursor lactase to the active mature enzyme. The defect appears confined to lactase because normal processing of sucrase-isomaltase was demonstrated in this subject. Nsi-Emvo et al. suggested a similar mechanism to account for their observations in a model for the postweaning decline of lactase in rat intestine (16).

The significance of two distinct molecular mechanisms responsible for the regulation of lactase expression is unknown. It is conceivable that the different phenotypes may be related to differences in the ethnic background of the subjects studied. Subject 4 was unique in having Native American heritage, raising the possibility that the defect resulting in phenotype II deficiency may be more prevalent in this racial group. On the basis of our studies, phenotype I deficiency may be the more commonly expressed type of adult hypolactasia.

\section{Acknowledgments}

We are indebted to Dr. Lawrence Kahan for his invaluable assistance in the preparation of monoclonal antibodies.

This work was supported by grant AM-13927 from the National Institute of Arthritis, Diabetes, and Digestive and Kidney Diseases and by Veterans Administration Research Funds. Dr. Lloyd was supported by the University of Wisconsin Clinical Nutrition Center and National Institutes of Health grant 5P30-AM-26659 and by National Institutes of Health Clinical Investigator Award K08 Dk01789.

\section{References}

1. Welsh, J. D., J. R. Poley, M. Bhatia, and D. E. Stevenson. 1978. Intestinal disaccharidase activities in relation to age, race, and mucosal damage. Gastroenterology. 75:847-855.

2. Simoons, F. J. 1978. The geographic hypothesis and lactose malabsorption: a weighing of the evidence. Am. J. Dig. Dis. 23:963980.

3. Mantei, N., M. Villa, T. Enzler, H. Wacker, W. Boll, P. James, W. Hunziker, and G. Semenza. 1988. Complete primary structure of human and rabbit lactase-phlorizin hydrolase: implications for biosynthesis, membrane anchoring and evolution of the enzyme. $E M B O$ (Eur. Mol. Biol. Organ.) J. 7:2705-2713.

4. Kruse, T. A., L. Bolund, K.-H. Grzeschik, H. H. Ropers, H. Sjostrom, O. Noren, N. Mantei, and G. Semenza. 1988. The human lactase-phlorizin hydrolase gene is located on chromosome 2. FEBS (Fed. Eur. Biochem. Soc.) Lett. 240:123-126.

5. Dahlqvist, A. 1968. Assay of intestinal disaccharidases. Anal. Biochem. 22:99-107.

6. Lloyd, M. L., and W. A. Olsen. 1987. A study of the molecular pathology of sucrase-isomaltase deficiency. A defect in the intracellular processing of the enzyme. N. Engl. J. Med. 316:438-442.

7. Burke, T., M. Lloyd, V. Lorenzsonn, and W. Olsen. 1988. Synthesis and intracellular processing of aminooligopeptidase by human intestine. Gastroenterology. 94:1426-1431.

8. Laemmli, U. K. 1970. Cleavage of structural proteins during the assembly of the head of the bacteriophage T4. Nature (Lond.). 227:680-685.

9. Heukeshoven, J., and R. Dernick. 1985. Simplified method for silver staining of proteins in polyacrylamide gels and the mechanism of staining. Electrophoresis. 6:103-112.

10. Galfre, C., and C. Milstein. 1981. Preparation of monoclonal antibodies: strategies and procedures. Methods Enzymol. 73:3-46.

11. Skovbjerg, H., E. M. Danielsen, O. Noren, and H. Sjostrom. 1984. Evidence for biosynthesis of lactase-phlorizin hydrolase as a single-chain high-molecular weight precursor. Biochim. Biophys. Acta. 798:247-251.

12. Naim, H. Y., E. E. Sterchi, and M. J. Lentze. 1987. Biosynthesis and maturation of lactase-phlorizin hydrolase in the human small intestinal epithelial cells. Biochem. J. 241:427-434.

13. Buller, H. A., R. K. Montgomery, W. V. Sasak, and R. J. Grand. 1987. Biosynthesis, glycosylation, and intracellular transport of intestinal lactase-phlorizin hydrolase in rat. J. Biol. Chem. 262:17206-17211.

14. Bolton, H., M. W. Ho, J. Potter, T. King, A. J. Furth, B. Griffiths, D. Swallow, and S. Povey. 1985. Immunochemical characterization of lactase in subcellular fractions of human jejunal enterocytes. Biochem. Soc. Trans. 13:97-98.

15. Jonas, M. M., R. K. Montgomery, and R. J. Grand. 1985. Intestinal lactase synthesis during postnatal development in the rat. Pediatr. Res. 19:956-962.

16. Nsi-Emvo, E., J.-F. Launay, and F. Raul. 1987. Is adult-type hypolactasia in the intestine of mammals related to changes in the intracellular processing of lactase? Cell. Mol. Biol. 33:335-344. 